\title{
Advantages For Portfolio Management Through Cost Scaling Equations for Offshore Wind Turbine Components
}

\author{
Maximilian MEISSNER and Michal GREGUS
}

Comenius University, Bratislava, Slovakia

Correspondence should be addressed to: Maximilian MEISSNER; meissner2@uniba.sk

Received date:18 May 2021; Accepted date:28 August 2021; Published date: 13 January 2022

Copyright (C) 2022. Maximilian MEISSNER and Michal GREGUS. Distributed under Creative Commons Attribution 4.0 International CC-BY 4.0

\begin{abstract}
This paper presents the key concerns of offshore wind turbine Original Equipment Manufacturers' (OEMs) Product Portfolio Management (PPM) functions for the predicted turbine growth. In addition, it provides possible improvements within the portfolio decision process through available cost forecast equations for turbines' main components. This is done by answering the research question "Will offshore wind OEMs' PPM benefit from cost forecast equations for turbines' main components within their portfolio decision process?" The answer to this question is found through an extensive literature review of product portfolio decisions within PPM in the wind industry and through interviews of key experts from a leading offshore wind turbine OEM. The method of qualitative content analysis as outlined by Mayring has been used to analyze the interviews and interpret the findings. It was analyzed if offshore wind turbine OEMs' PPM agrees to the from the literature predicted turbine growth and what they see as the real risks and cost drivers correlating with it. In addition, it was evaluated if cost forecast equations could improve the CAPEX estimations in the portfolio decision process. The presented results will be used in future research to create accurate cost forecast models for turbines' main components with the aim of an overall turbine CAPEX scaling model.
\end{abstract}

Keywords: Portfolio Management, Portfolio Decision Making, Offshore Wind Turbines, Cost Scaling, Renewable Energy.

\section{Introduction}

Climate change is real; this is one thing scientists agree on! The average temperature was never higher than in the 20th century and it's still rising. Therefore, in December 2015, the Paris Climate Agreement has been signed by the United
Nations Framework Convention on Climate Change. The goal of this pact is to keep the global average temperature beneath $2^{\circ} \mathrm{C}$ compared to pre-industrial levels. To reach this goal, member states declared that they would reduce greenhouse gas emissions by the end of the century, to up to $25 \%$ in 2040 and $35 \%$ in 2050 (IRENA, 2019).

Cite this Article as: Maximilian MEISSNER and Michal GREGUS (2022)," Advantages for Portfolio Management Through Cost Scaling Equations for Offshore Wind Turbine Components", Communications of the IBIMA, Vol. 2022 (2022), Article ID 942296, DOI: 10.5171/2022.942296 
Particularly, offshore wind turbines, which have several advantages compared to onshore turbines, will drive the progress towards the low emission targets. By the end of 2020, there is around 25.014 MW of constructed offshore wind capacity available (Jaganmohan, 2021). The forecasts for offshore wind are extremely positive, as offshore wind can compete, since 2018 in Europe without subsidies, with all conventional energy sources (Alastair Dutton et al., 2019, 4). Projections suggest that the an annual growth from 2019 to 2027 will average $11 \mathrm{GW}$ per year, a fivefold increase over annual installations from the preceding eight-year period (Alastair Dutton et al., 2019, 6). Other sources go beyond that and predict around $28 \mathrm{GW}$ for 2030 and even $45 \mathrm{GW}$ per year for 2050. The overall installed offshore wind capacity is predicted to reach $228 \mathrm{GW}$ and up to $1000 \mathrm{GW}$ in 2030 and 2050, respectively. This would mean a yearly installation of around $45 \mathrm{GW}$ in 2050, which would be an around ten-fold increase compared to the 4,5 GW added in 2018 (IRENA, 2019)(Meißner, 2020d).

The assumption on which the forecasts are based is that the electricity production costs or Levelized Cost of Energy (LCOE) of offshore wind will continue to decrease (IEA, 2019). Today, in order to lower the LCOE of offshore wind, one measure by the turbines' Original Equipment Manufacturers (OEMs) is to increase the turbine rating and size of the rotor, as this increases the annual energy production and decreases the installation costs per wind farm. In 2020, Siemens Gamesa announced a 14 MW turbine with a $222 \mathrm{~m}$ rotor diameter (Siemens Gamesa Renewable Energy, 2020). Vestas Wind Systems went one step beyond in 2021 and announced a $15 \mathrm{MW}$ turbine with a $236 \mathrm{~m}$ rotor (Vestas Wind Systems A/S, 2021). Scientists and researchers predict that turbines will reach $20 \mathrm{MW}$ with rotors of 300 meters in the next decade (Barla, 2019).

But, according to the square-cube law, the material costs of larger turbines will be significantly higher (Huerta, 2006). In order to avoid these cost increases, innovations and new technologies must be deployed. In order to offer the right turbine in terms of size, rating, technology and costs on the right time in the future, wind turbine OEMs are using product portfolio management departments.

\section{Theory, Research Question and Hypotheses}

\section{Product portfolio Management}

Product Portfolio Management (PPM) is used since the 1960s and is about allocating the resources for introducing the business's products and technologies' objectives (Cooper et al., 1999; Jugend et al., 2017). (Lahtinen et al., 2019, 1) found, in their extended literature research, that the main available literature about PPM is focusing on the management of new products introduction and R\&D projects. This is an indication that PPM is mainly focused on the early phases of the product's lifecycle process - in the product's definition (Tolonen et al., 2015). According to (Lynn et al., 1999), new or updated products will achieve cost reductions and functional improvements, which will lead to the company's competitive market position (Hänninen et al., 2013). Nevertheless, PPM also decide the discontinuation of a product (Jugend and Da Silva, 2014). Overall, with its product and portfolio decisions, PPM is impacting the long-term growth and financial success of the company and should be based on facts and figures and not on estimations (Mikkola, 2001).

A decision for a product or a whole portfolio is typically made based on business strategy, project risk and product value as well as forecasting the estimated material cost of the product. However, due to the timing when product portfolio decisions are made, the decision is very complex (Cooper et al., 1999) since it is very challenging to predict the future cost of a not yet existing product (Lin, 2008). Mistakes in this early decision making process can lead to poor commercial attractiveness, a transmission of immature technology and higher than expected development expenses (Jugend and Da Silva, 2014). To generate the best portfolio results - a matrix organization with cross functional teams have demonstrated best results (Jugend and Da 
Silva, 2014; Olson et al., 2001). In addition, Cooper et al. already specified, in the year 1999, that PPM is using financial models and indices, the option pricing theory and strategic approaches in order to make the right portfolio decision (Cooper et al., 1999).

The organizational set up of PPM is discussed intensively in the literature. Olson et al. found out that PPM's success is not only limited to cross functional teams between PPM and R\&D as published in the main literature which they analyzed. They pointed out that operations and marketing also play a key role in the success of PPM's decisions (Olson et al., 2001). Further, Jugend et al. also analyzed the organizational structure of PPM through intensive literature reviews and pointed out that next to cross-functional teams, matrix organizations also work for the successful integration of new product introduction processes (Jugend and Da Silva, 2014). Brettel et al. added marketing as an important stakeholder in the PPM decision process (Brettel et al., 2011). Procurement, as a relevant stakeholder, could not be found in the literature.

\section{Cost Prediction Methodology for Offshore Wind Turbines Within PPM}

As already mentioned by Cooper et al. in 1999, PPM is responsible for making portfolio decisions, and this includes predicting the future cost of the products. For this, over $77 \%$ of businesses' PPM teams are using e.g. financial models (Cooper et al., 1999; Cooper et al., 2001). In order to calculate the expected commercial value of a new project, the future income stream needs to be predicted - which includes the future material costs of the product (Cooper et al., 2001). There are no publications available about how PPM organizations at offshore wind OEMs are estimating the future cost. However, it is a common sense to use the LCOE as a reference (BEIS, 2020; Bosch et al., 2019; Bruce Valpy et al., 2017; Crabtree et al., 2015) which will be assumed as a baseline for cost prediction at offshore wind suppliers' PPM teams.

Beis et al. defined the LCOE, which is commonly used, as the discounted sum of costs over lifetime divided by the discounted sum of energy produced (BEIS, 2020). Within the discounted sum of costs over lifetime, the turbine costs which include the nacelles, towers and blades, represent up to $45 \%$ of the whole wind farm CAPEX investment (Brian Snyder and Mark J. Kaiser, 2008; Crabtree et al., 2015; IRENA, 2019; Ove Arup \& Partners Ltd). Offshore wind OEMs' PPM needs to predict these costs around four years ahead of serial production. Research showed that there are no accurate cost models available to predict the future CAPEX of offshore wind turbines. This could lead to no commercial attractiveness for the new products. With the increased size of offshore wind turbines, compared to the OPEX-, the CAPEX-portion within the LCOE also increases, which requires the need for an increased accurate cost prediction (Meißner, 2020c).

Through this offshore wind, OEMs' PPM is forced to increase the accuracy of the forecast of material costs. However, as the literature proved, the current published CAPEX forecast models are not accurate enough (Meißner, 2020c).

\section{Research Question and Hypotheses}

The literature review about the theory of PPM and wind turbine cost estimation methodology was used as a baseline for the used interview questionnaire. This research paper aims to analyze the main concerns of Offshore Wind Turbines (OWT's) OEMs regarding the portfolio decision making process and if they will benefit from cost forecast equations for wind turbines' main components to narrow the discovered research gap.

For this, the study within this paper is developed around the following research question, which guides through the research process.

R: Will offshore wind OEMs' Product Portfolio Management benefit from cost forecast equations for turbines' main components within their portfolio decision process? 
To answer this question, this paper is analyzing the following three hypotheses:

H1: The predicted offshore wind turbine growth is correct.

$\mathrm{H} 2$ : The disproportionate increase in material costs for larger offshore turbines is the biggest challenge for turbines' OEMs.

H3: Cost scaling equations could help to improve the portfolio decision making process.

The aim of this research is to present the main challenges for offshore turbines' OEMs within the portfolio decision making process. In addition, it should be investigated if the assumption of the growth of offshore wind turbines is expected from OWT's PPM perspective. Special attention is paid to the advantages of future material cost equations for offshore wind turbines' main components.

\section{Research Design and Data Collection}

\section{Research Design and Strategy}

In this type of research, the investigator concludes the significance of his findings and aims at generalizable conclusions. The research was carried out by analyzing literature, interviewing experts of a wind turbine OEM, as well as analyzing internal documents.

The study was started by carrying out a literature review to have the necessary understanding of the discussed topics, and to map the existing practices and knowledge, regarding product cost estimations for offshore wind turbines' components and CAPEX. This part was published in earlier research by (Meißner, 2020c). The literature review was conducted by keyword searches on Google Scholar to search for articles relevant to the topic. The relevant keywords used include several variations of the product portfolio decision process, LCOE, wind turbine costing, cost estimation and forecast. The identified documents and articles were precisely studied to evaluate their applicability.

The presented research question with its hypotheses will be answered using a qualitative research design with semi- guided expert interviews. The results and insights of the conducted literature review were a key input for the formation of the interview questionnaire in order to support the interviewer. Answers were categorized and assigned to the predefined hypotheses in order to answer the research question. This theory building approach explores theory building blocks from material in a predominant inductive process (Mayring, 2010).

\section{Data Collection}

The data collection includes two semistructured expert interviews with wind turbine OEM employees who hold deep expert understanding and are responsible for the future product portfolio including the material cost prediction. The experts were known to hold the relevant knowledge of the studied issues, and the ability to analyze the current practices and situation. Each interview was recorded to ensure the detailed examination of the interview. The selected employees included people from an offshore wind OEM's PPM organization.

The titles of these employees include: Head of Wind Offshore Portfolio Management, and Commercial Director Offshore Portfolio Management and Cost Competitiveness.

The interviews have been conducted via Microsoft Teams in a one-on-one setting and lasted 39 and 42 minutes. Interviewers have been at their home places. During the interview, the interview guide was used; however, the sequence of questions varied according to the respective interview partners, and the selection of questions was adapted individually according to the course of the conversation. This made it possible for the interview to take place as naturally as possible, which was intended to provide the most realistic possible picture of the interviewees' opinions. The interview partners were not aware of the questionnaire in order to be able to answer the questions more spontaneously without preparation. The interviews were recorded through the recording function in Microsoft Teams. Following the interviews, they were transcribed using the transcription software. 


\section{Data Analysis}

The statements obtained in the expert interviews were converted into text form using the easytranscript transcription software.

The complete transcriptions of the interviews were subsequently compiled and coded with the aid of a self-created Excel spreadsheet. The formulated codes are based on the research question and hypotheses, and were applied to all interviews. Meaningful, content-related categories were formed using a combination of inductive and deductive procedures. According to the qualitative content analysis, these categories are described synonymously with variables, characteristics or characteristic values. Extracting the individual text passages and assigning them to the defined categories enable the optimal comparability and provide an overview of the qualitatively valuable and evaluable text components (Kuckartz, 2016).

The following core criteria formulated by Mayring serve as quality criteria for the qualitative research and evaluation of the results for this work: Procedural documentation, argumentative interpretation safeguards, ruleboundedness, proximity to the object, communicative validation, and triangulation (Mayring, 2010).

\section{Results}

In the following section, the empirical data from the individual interviews are presented as condensed results. For this purpose, the statements of the interview partners are assigned according to the formed categories.

C1 Results: Current and future offshore turbine growth

SC1.1 - SC.1.4

Researchers predict a significant turbine growth within the next decade and the interviewed experts tend to agree on this trend. For the question regarding whether they foresee a limit, the answer was clear
"No, not yet" (I1, (Meißner, 2020a), 37p.1), "it is hard to say" (I1, 60, p.2) and "I see no reason why that trend would not continue" (I2, (Meißner, 2020b), 35-40, p.1). Maybe the exponential growth is "flattening out" (I1, 41, p.1) and "the pace is slowing down" (I2, 35-40, p.1), but the experts did not want to predict a limit for the size of offshore wind turbines. "Usually in the past, people saw limitations in the kilowatt, megawatt and even multi-megawatt range" (I2, 35-40, p.1) and they were all wrong. One interviewee explained that you can only "find a theoretical optimum" when "you freeze all innovations (...). But in the nature of innovation (...), it becomes a bit unplannable, as you're not sure if your new idea can be matured - but if these ideas became real, this would be the drivers for further growth" (I1, 41-52, p.1-2). In line with this, another expert said: "the technological breakthrough and also the development of the supply chain have led to bigger and bigger turbines. So, I see no reason why that trend would not continue" (I2, 35-40, p.1).

The experts expected growth of turbines in line with the advantages they enumerate. For example, "with the growing number of plate capacity, you do have fewer positions that help a lot in fewer foundations and also in less service effort" (I1, 25-28, p.1), which leads to an overall reduction of the LCOE. This is in line with what another expert elaborated that with "bigger turbines out in the field, you basically save foundation costs by taking positions out, which is an important driver in the offshore business case" (I2, 19-21, p.1). Moreover, one expert mentioned that "foundations don't scale" like turbines and "if you double the size of the turbines, a foundation doesn't cost double (...) and this is where you really get the savings in" (I2, 52-56, p.2)."In addition, saving also OPEX cost for our customers." (I2, 19-21, p.1). Additionally, "you only have to visit one turbine to do service and to do trouble shooting, so you actually get a better efficient set up there" (I2, 56-57, p.2). This more efficient set-up saves OPEX costs and lowers the LCOE as well. At the end, this is another reason for the future growth of offshore wind turbines. 
The experts have given an outlook only till 2030 as they didn't want to speculate for 2050 for example. One expert mentioned that for 2030, "external analyst reports think that turbine sizes of $20 \mathrm{MW}$ could be around. (...) Yeah and they might be right" (I1, 65-69, p.2) and "I think something around the $20 \mathrm{MW}$ range is not unlikely to happen" (I1, 74-77, p, 2). Another expert mentioned that "I think something around the 20MW range is not unlikely to happen" $(\mathrm{I} 2,75-76, \mathrm{p} .2)$ in 2030 . For the rotor size of a 20 MW turbine, one expert elaborated that "it's hard to say but at least what we have seen so far is the rotor loading, which is in the end what is driving, and if you extrapolate from what we see today in terms of (...) Watt per square meter (...), I think you will probably get in a range of whatever 250 - 300 meters" (I2, 80-84, p.2).

For an OEM's PPM, this means that in the future, they "always consider what is the biggest (...) technical feasibly turbine (...) when calculating portfolio decisions" (I2, 64-68, p.2).

C2 Results: Material cost portion increase is the main challenge for growing OWT.

Research showed that within the LCOE calculation of offshore wind, the CAPEX portion will increase through the growing turbines compared to the OPEX (Meißner, 2020c). This is also in line with what experts are referring too. One interviewee pointed out that "there is basically a tendency that this (CAPEX) goes up when you go to bigger turbines. (...) The weighting is probably going up especially since we have savings in the other areas like OPEX and the foundations we discussed before" (I2, 129135, p.3).

Nevertheless, this trend comes along with challenges. One expert agreed to the literature (Meißner, 2020c) that "the main challenge is (...) the square cube law (...) that means if (...) you're increasing the swept area of your rotor by a factor of two,(...) then you will over proportional increase the loads, and hence you will have over proportional increase of the cost of the load carrying parts like the hub (...), which means that the turbine itself per Megawatt would even get more expensive if you wouldn't have any technology innovations" (I1, 19.
25, p.1). Another interviewee said that they "see that the turbines are getting bigger - if you look at the cost per megawatt that you install, it is actually hard to keep that stable" (I2, 48-51, p.2). This increase in material costs isn't coming "from a technical complexity, but from a simply supply base like castings. I think it is also definitely one of the key concerns" (I2, 161-164, p.4). The expert is highlighting that "one big issue is obviously the supplier's capabilities, because we are talking sizes - if you talk about castings, if you talk about bearings. So, components sizes which are new to the industry or to any industry. (...) But there is not really any other industry that also requires components of that size" (I2, 142146, p.4). Therefore, the limited supplier's base is driving the component cost in addition to the over proportional growth of the main components.

Another challenge which comes along with the turbine growth is that the increased costs per turbine lie within the OEM, and the generated savings through bigger turbines lie within the customer. One expert mentioned that "of course, it's a challenge that the turbine is in our scope, whereas at least a lot of the savings, due to fewer positions, are in the customers' scope. For example, for all the service benefits, it's a challenge to negotiate a fair split of the value that is being created by going larger" (I1 2533, p.1). A further challenge is "the increased size of components to handle where we see that the supplier's landscape is limited" (I2, 22-24, p.1). Furthermore, in terms of the transportation and installation of larger offshore turbines, an expert elaborated that "if you look into the transportation and installation capabilities (...) and installation vessels which are out in the market, there are limitations" (I2, 24-25, p.1). These limitations in available installations ships increase the costs and make the growth a challenge.

Beside the quantitative challenges, there are qualitative ones. In order to keep the costincrease limited, OEMs try to improve their products with technology innovations. These innovations come with a certain risk "and risks are plenty. There are technologyrisks; you simply (...) don't get a technology to work. Or you have some failure rates that 
are above expected. These would be technology risks" (I1, 206-213, p.5). However, new technology introduction also leads to "timing risks, for example you're simply just too slow, or you're not ready when you have promised to be ready. Normally, we have quite significant LDs (Liquidated Damages) to pay" (I1, 206-213, p.5). However, the LDs are not only the issue. If the product is not ready on time, the OEM will "miss a bidding window, for example in the UK, (...)if you don't have a product for this auction, then you're simply not in the race and there will be an allocation for around 8-9 GW volume. So, timing is important" (I1, 210-227, p.5).

C3 Results: Improvements through available cost scaling equations

The interviewed experts have agreed that today's component cost scaling is not accurate. For the component level, they mentioned that "on some, we are more off than others" (I1,294-301, p.7) and "you're off on one component, probably there is another to offset" (I2, 224-231, p.5-6). They agreed on this point; however, the experts also argued that "the sum is maybe not as wrong as each individual part" (I1,294-301, p.7) and "if you look at overall values - there are pretty spot on" (I2, 224-231, p.5-6). This means that the overall turbine cost estimations, in their opinion, are on a good level. An interviewee called this a "certain pooling effect" (I2, 224-231, p.5-6). With this, the current way of component cost scaling carries a certain risk and uncertainty when product portfolio decisions are made. This conclusion is also underlined by an expert which explained that "there have been surprises in the past and that usually comes if you hit a certain scaling threshold where basically established processes can't be used anymore and you don't see that coming. There can be significant extra costs coming up which you're basically not planning for" (I2224-231, p.5-6).

As for the question regarding whether there are any security factors applied within the current component cost estimations process, the answer was clear. The experts commonly agreed that even with the knowledge of the described uncertainties, no security factors are applied to the current cost estimations. For example, one expert said: "when we look into the business case, we usually don't take safety factors in the calculations" (I2, 233-242, p.6).

There are certain advantages the experts can see in the existence of component cost scaling equations. In relation to the mentioned uncertainties in the cost scaling, their existence "will reduce risk" (I1, 329, p.9) and it "would be good to have more accurate forecasts (...) as you look into a huge range of uncertainties" (I2, 349-364, p8). One expert mentioned that you could offer the new product earlier in a bidding process for a new offshore wind project and that would be a huge advantage as OEMs are currently even more forced to offer their products even before they have built a prototype. An interviewee said: "that is actually happening and that is even more often in the future and the more clarity we can have on costs and also on the technical performance at an early point - the better the lower is the risk". So, the sooner the OEMs can do certain material costs estimations, the higher is the certainty to an early stage. So, he mentioned that "the earlier we know, the sharper we can offer, the higher is the probability that we can win, and the lower is the risk that we face bad surprises" (I1, 432-449, p.10).

Another expert outlines the same advantage, adding the saving of manual effort which is done for current cost estimations. As the expert mentioned "we would for sure save a lot of the footwork - going to experts, and asking them for their guesses with limited amount of input data. That of course would be more formalized. And you could also be sure to be faster and you could reduce risks by, let's say, putting it more on a fact base and not so much on an expert's view. And the earlier you get the facts in and the more stringent you organize the process, the less risk you have and the faster you can be. So, there is no doubt that this would add value" (I1, 393-400, p.9).

However, the experts also mentioned some concerns and conditions that the forecast equations need to fulfill in order to be trusted. One expert said that the equations "very much depend on the assumptions you take - and you need to revisit them on a regular basis and see how the industry is changing" (I1, 488-497, p.11). In this sense, 
he is pointing to future technology changes. For example, if you would keep the cost equations as they are and don't develop them further over time, they will not capture these innovations and would estimate the future costs to high. And the same counts for suppliers' manufacturing capabilities which he is referring to as well. Another expert agreed on that, pointing to the data from the past. If the equations have technology innovations included, the future costs can be underestimated, but "then, you would have probably a super competitive product, because at an early stage, you would already consider technologies that are not mature" (I2, 449-454, p.10). Both cases need to be considered and should be transparent to the users of the future cost estimation equations.

One expert pointed out a benefit of cost forecast equations which is the difficulty to quantify. He mentioned that you "would never translate that into a concrete margin upside or whatever" as you could still under- or overestimate the costs. But for sure it would "lower the risk. (...). Once it is sure, it is helping to reduce risk and it's therefore a good thing" (I1, 410-428, p.910).

\section{Discussion}

At this point, a discussion of both the content and the methodology should take place in order to be able to answer the research questions. This will be done through the interpretation of the results and with the help of the literature. The discussion of the content refers to the critical reflection of the statements of the interview partners in the context of theory and research. The methodological discussion refers to the selection of the chosen interview partners and the procedure within the framework of the research design.

\section{About the Methodology}

First, an analysis of the existing literature was conducted, assessed for relevance, and considered accordingly. For the topic, the relevant literature was very rare, as the cost impact of the offshore wind turbine growth has not been investigated extensively, even not for onshore turbines. The literature review was conducted by keyword searches on Google Scholar to search for articles relevant to the topic. The used keywords relate to and include several variations of the product portfolio decision process, LCOE, wind turbine costing, wind turbine cost estimation and forecast. It was a challenge to point out the relevant literature as the topic is not well researched till today.

The open-mindedness of the interview partners, who were experts for this work, was particularly surprisingly positive. The challenge of finding a meaningful research unit for the sample, which is otherwise common for qualitative research, does not apply in this case. However, a higher sample number would have the advantage of being able to derive more generally valid statements (Flick, 2019). Additionally, a following quantitative study, which builds on the results of this work, would help in supporting the qualitative results with numbers. The validity is certainly to be considered under restriction, since the data collection method was a random sample, which means that the decision of who to include in the sample was not subject to any elaborated sample planning, but only to the discretion of the authors of this work. In addition, it is worth mentioning that the interviewed experts work for the same turbine OEM. As a result, the sample is biased and not representative, because the experts selected in this way do not represent a cross-section of the industry. The advantage, however, is that at least initial, realistic impressions can be gained quickly and easily.

During the interview, it was challenging to ask the individual interviewees identical questions, as the answers and general topics took on a very strong momentum in the course of the conversation. Nevertheless, comparable or contrastable answers were to emerge at the end for an evaluation of the results without any influence on the part of the interviewer. Thus, the answers that did not lead, in a target-oriented way, to answering the research question were intentionally not used in the coding table.

In retrospect, the authors consider the decision regarding a qualitative research design to be correct. Because fundamentally, the qualitative research 
design, due to its characteristic openness (Mayring, 2010) not only allowed for a certain depth of the topic, but also for surprising answers, such as "we need to know our supplier's capabilities; we know at least the transport limits; in order to avoid that we are, let's say, getting these, let's say, discontinued; this jumps in costs; Because this is the biggest risk" (I1, 290294, p.7). With a quantitative questionnaire, answers like these would very likely not have been recorded, as the authors would not have even considered these answers as an option. The topic would therefore have been predefined from the outset in a much narrower and more subjective way from the authors' point of view.

\section{About the content}

At this point, the results will be interpreted and evaluated. For this purpose, the research question will be answered by answering and discussing the hypotheses. The overarching research question is "Will offshore wind OEMs' Product Portfolio Management benefit from cost forecast equations for turbines' main components within their portfolio decision process?" To answer this question, this paper is analyzing the three hypotheses with the help of the statements of the build categories.

H1: The predicted offshore wind turbine growth is correct.

This research confirms that the analysts predicted the size increase of offshore wind turbines within the next decade. The interviewed experts, in line with the literature, predicted a further growth. For 2030, they foresee turbines in the range of 20 megawatt and a rotor diameter between 250 - 300 meters. However, this also seems to be just an intermediate stage. The interviewees didn't want to predict any limits for the future growth for offshore wind turbines. The predicted size increase will, according to the experts, slow down but this depends on the future technology innovations which are the drivers for bigger turbines. The continuous growth of turbines is expected as long as it pays off to have fewer positions per wind farm. The customer business case with fewer turbines improves with less foundation, installation and operational costs. All of this leads to a lower LCOE and a higher internal return of investment (IRR) for OEMs' customers. With this, a discontinuation of the trend for larger turbines cannot be foreseen, which is a fundamental confirmation for the need of cost forecast equations for offshore wind turbines' main components.

The hypothesis can be answered clearly with yes. There are no indications that offshore wind turbines will stop growing within the outlook the experts could give. But to enable the growth, technological innovations are needed.

$\mathrm{H} 2$ : The disproportionate increase in material costs for larger offshore turbines is the biggest challenge for turbines' OEMs.

As stated in C1 and H1, the main advantages for larger turbines lie in the scope of the customer and not within the OEMs. The cost reduction for OPEX and installation costs and at the same time the increase in material costs increase the absolute portion of turbine CAPEX in the LCOE equations. As the material costs lie within the OEM's scope, it is to be expected that their main challenge is the growth of the main components. Because through the squarecube-law, the weight and cost of materials increase over proportionally with the turbine growth (Meißner, 2020c), as confirmed by this research. The interviewed experts described the over proportional growth of the main component as their main challenge. Further, with the increase of components, the supply chain risk increases. On one hand, on the main component suppliers but on the other hand as well on the turbine handling including the installation vessels and cranes.

The increasing costs and risk for the OEMs force them to introduce technology and material innovations which aim to reduce the material costs. However, the experts described that these innovations add new risks for the OEMs. New materials and technologies must be tested and verified, so the risk is high when these innovations are not on time for serial production or do not perform as expected regarding the new product. It seems that these challenges are known to the industry at the OEM and the customer site, leading to the main challenge, 
which is to negotiate a fair split between the parties of the cost reduction benefit on one hand, and the cost, technology and supply chain risk on the other hand.

To answer $\mathrm{H} 2$, it can be said that the disproportional increase of the material cost portion is an extreme challenge for the turbines' OEMs, which is closely related to the increasing size of turbines' components and the risk scenario for new technologies and innovations coming along with it. It seems that this challenge, where the upsides lie within the customer and the downsides within the OEM, is known. So, the main challenge seems to be the negotiation of the fair split between the commercial and risk up- and downsides for future larger offshore wind turbines.

H3: Cost scaling equations could help to improve the portfolio decision making process.

The results from $\mathrm{H} 1$ and $\mathrm{H} 2$ underline that the predicted growth of offshore wind turbines is real, and this sets the clear foundations for the need of component cost scaling equations within the portfolio decision making process.

Within this research, it has been identified that the current component cost estimations within the portfolio decision process are not precise and guesses from experts are more qualified, especially when components hit certain limits related to transport or to manufactures' capabilities. Till now, it seems that the off-rate of larger turbines get the risk of wrong estimates due to the square-cube-law. Due to this fact, it seems surprisingly that even with the knowledge of inaccuracy, there are no safety margins included in the cost calculations within the portfolio decision process.

So, it is not surprising that the experts see benefits in available cost scaling equations for offshore main components, especially in terms of risk reduction as the equations could help reduce the risk of wrong cost estimations, since these equations would be built on transparent rules and data. At the same time, it would reduce the manual effort of collecting and discussing the cost estimations for each individual main component. The profound knowledge of the turbine costs at the early stage of the portfolio decision making process could also lead to a faster decision making and subsequently to the fact that the OEM can offer the new turbine earlier to the customer, which would be a huge advantage against the other OEMs in terms of timing .

Beside the advantages of the cost scaling equations, there are some valid concerns related to the data quality and the considered technical assumptions. As the equations would be built on data from the present and the past, the cost prediction through the created scaling equations would consider the technology innovations from the past, and this is also expected for the future. In addition, the equations must be constantly reviewed as each new or changed data point will change the equations. So, the created equations should not be fixed in time and should regularly be updated to guarantee the best value to PPM in the product portfolio decision process. This feedback must be taken seriously and considered into the cost scaling equations built.

To answer H3, it can be clearly stated that OEMs can benefit from the main component cost scaling equations within their product portfolio decision process, especially in terms of the risk reduction and improvement of accuracy in early cost estimations as well as the reduction of manual effort which is highlighted under the conditions that the equations are regularly updated and transparent based on technology assumptions.

R: Will offshore wind OEMs' Product Portfolio Management benefit from cost forecast equations for turbines' main components within their portfolio decision process?

The summary of $\mathrm{H} 1$ underlined the expectations that offshore wind turbines will further grow. To this point, there can be no limits foreseen neither in terms of the rotor's size and the hub's height nor in the electrical rating. This sets the foundation and confirms the need for cost scaling equations for offshore wind turbines' main components. Another important basic assumption has been confirmed. H2 laid out that compared to the OPEX and installation costs, the over proportional increase of material cost is the main challenge for 
turbines' OEMs. From this result, it can be deduced that the future focus of turbines' OEMs will shift, with the increasing size of the turbines, to the material costs, as the spending on materials will directly influence their profit margin. Therefore, it is important for the cost assumptions in the portfolio decision process to be as accurate as possible, since wrong baseline cost assumptions for the new product could have a negative impact on the OEM's profit margin.

H3 confirms that Product Portfolio Management organizations from offshore wind turbines' OEMs can benefit from cost forecast equations for turbines' main components. Their availability will improve the accuracy of the early cost prediction and decrease the manual effort for creating them within the portfolio decision process. Overall, these equations will reduce risks for the OEMs and increase the confidence in the baseline cost assumptions within the decision process. This could lead, according to the experts, to a faster decision-making process with the chance to offer new products earlier to the customer, which would lead to a market advantage compared to other turbines' OEMs.

However, in order to fulfill these expectations, the component forecast equations need to be trusted and well maintained. The data accuracy must be high and constantly up to date, and their technology assumptions must be transparent for every user as well.

\section{Conclusion and outlook}

The objective of the present research paper was to use a qualitative research design with the help of expert interviews to investigate the need for offshore wind turbines' main components' cost scaling forecast equations within the product portfolio decision process at an OEM. Therefore, the conditions for the existence of these equations, the growth of future turbines and the increasing importance of material costs within the product portfolio decision process were investigated. Finally, the advantages and conditions for these cost scaling equations where laid out.
This paper confirmed that the baseline assumption of the future growth of offshore wind turbines is correct. It was also elaborated that the focus on the material costs of the turbines' components will increase at the OEMs and that the accuracy of the cost prediction must increase for the future portfolio decision making.

Till now, the scientific literature has not yet investigated the conflict between OEMs and their customers in relation to the growing size of wind turbines and the unfair split of cost savings and additional costs. Therefore, further research is recommended in this area. In this case, it looks like the offshore wind industry is further in its development than the literature. One possible explanation can be that the offshore wind industry is a rather young industry and has not been well researched yet. This paper contributes to spread awareness of the gap in the literature and, at the same time, sets the foundation for the formation of cost scaling equations for offshore wind turbines' components.

The results and findings of this work should be confirmed and further researched as recommended through a quantitative research with industry wide experts. In this further research, the diversity of the group of experts can be increased as well.

\section{Acknowledgment}

This paper is an output of the science project at the leading offshore wind turbine OEM. It received no funding from external parties. The authors are grateful to the anonymous reviewers for their insightful and detailed comments, which have significantly improved this paper.

\section{References}

- Alastair Dutton et al. (2019). GoingGlobal. Expanding-Offshore-Wind-ToEmerging-Markets. The world Bank. Available online at http://documents.worldbank.org/cura ted/en/716891572457609829/GoingGlobal-Expanding-Offshore-Wind-ToEmerging-Markets (accessed 11/24/2019). 
- $\quad$ Barla, Shashi (2019). Next-Generation wind turbine models. Available online at

https://www.woodmac.com/reports/ power-markets-next-generation-windturbine-models-2019-328241

(accessed 7/19/2020).

- BEIS (2020). Electricity Generation Cost Report. Available online at https://assets.publishing.service.gov.u $\mathrm{k} /$ government/uploads/system/uploa ds/attachment_data/file/566567/BEIS _Electricity_Generation_Cost_Report.pd $f$ (accessed 2/22/2020).

- Bosch, Jonathan/Staffell, Iain/Hawkes, Adam D. (2019). Global levelised cost of electricity from offshore wind. Energy 189, 116357. https://doi.org/10.1016/j.energy.2019 .116357 .

- Brettel, Malte/Heinemann, Florian/Engelen, Andreas/Neubauer, Steven (2011). Cross-Functional Integration of R\&D, Marketing, and Manufacturing in Radical and Incremental Product Innovations and Its Effects on Project Effectiveness and Efficiency. Journal of Product Innovation Management 28 (2), 251269. https://doi.org/10.1111/j.15405885.2011.00795.x.

- Brian Snyder/Mark J. Kaiser (2008). Ecological and economic cost-benefit analysis of offshore wind energy. https://doi.org/10.1016/j.renene.200 8.11.015.

- Bruce Valpy/Giles Hundleby/Kate Freeman/Alun Roberts/Andy Logan (2017). Future renewable energy costs: Offshore wind. 57 technology innovations that will have greater impact on reducing the cost of electricity from European offshore wind farms.

- Cooper, Robert G./Edgett, Scott J./Kleinschmidt, Elko J. (1999). New Product Portfolio Management: Practices and Performance. The Journal of Product Innovation Management (Volume16, Issue 4). https://doi.org/10.1111/15405885.1640333.
- Cooper, Robert/Edgett, Scott/Kleinschmidt, Elko (2001). Portfolio management for new product development: results of an industry practices study. R\&D Management 31 (4), 361-380. https://doi.org/10.1111/14679310.00225.

- Crabtree, Christopher J./Zappalá, Donatella/Hogg, Simon I. (2015). Wind energy: UK experiences and offshore operational challenges. Proceedings of the Institution of Mechanical Engineers, Part A: Journal of Power and Energy 229 (7), 727-746. https://doi.org/10.1177/0957650915 597560 .

- Flick, Uwe (2019). Qualitative Sozialforschung. Eine Einführung. 9th ed. Reinbek bei Hamburg, Rowohlt Taschenbuch Verlag.

- Hänninen, Kai/Kinnunen, Tuomo/Haapasalo, Harri/Muhos, Matti (2013). Rapid productisation: challenges and preconditions. International Journal of Product Lifecycle Management 6 (3), 211. https://doi.org/10.1504/IJPLM.2013.0 55877.

- Huerta, Santiago (2006). Galileo was Wrong: The Geometrical Design of Masonry Arches. Nexus Network Journal $\quad 8$ (2), 25-52. https://doi.org/10.1007/s00004-0060016-8.

- IEA (2019). Offshore Wind Outlook 2019, 1-98. Available online at https://www.iea.org/reports/offshore -wind-outlook-2019.

- IRENA (2019). Future of Wind. Deployment, investment, technology, grid integration and socio-economic aspects. Available online at https://www.irena.org/publications/2 019/0ct/Future-of-wind.

- Jaganmohan, Madhumitha (2021). Cumulative offshore wind power capacity installations in Europe from 2006 to 2020. Available online at https://www.statista.com/statistics/2 71055/cumulative-european-offshore- 
wind-power-capacity-installations/ (accessed 3/27/2021).

- Jugend, Daniel/Da Silva, Sérgio Luis (2014). Product-portfolio management: A framework based on Methods, Organization, and Strategy. Concurrent Engineering 22 (1), 17-28. https://doi.org/10.1177/1063293X13 508660 .

- Jugend, Daniel/Luiz, Joao Victor Rojas/Jabbour, Charbel Jose Chiappetta/Silva, Sérgio Luis/Beatriz, Ana/Jabbour, Lopes de Sousa/Salgado, Manoel Henrique (2017). New Product Portfolio Management: Practices and Performance. Empirical Evidence from an Emerging Economy. Business Strategy and the Environment (Volume26, Issue8), 1181-1195. https://doi.org/10.1002/bse.1977.

- Kuckartz, Udo (2016). Qualitative Inhaltsanalyse. Methoden, Praxis, Computerunterstützung. 3rd ed. Weinheim, Bergstr, Beltz Juventa.

- Lahtinen, Niko/Mustonen, Erno/Harkonen, Janne (2019). Commercial and Technical Productization for Fact-Based Product Portfolio Management Over Lifecycle. IEEE Transactions on Engineering Management, 1-13. https://doi.org/10.1109/TEM.2019.29 32974.

- $\quad$ Lin, Ching-Torng (2008). New product portfolio selection using fuzzy logic, 114-118. https://doi.org/10.1109/IEEM.2007.4 419162.

- Lynn, Gary S./Abel, Kate D./Valentine, William S./Wright, Robert C. (1999). Key Factors in Increasing Speed to Market and Improving New Product Success Rates. Industrial Marketing Management 28 (4), 319-326. https://doi.org/10.1016/S00198501(98)00008-X.

- Mayring, Philipp (2010). Qualitative Inhaltsanalyse. Grundlagen und Techniken. Wieselburg.

- Meißner, Maximilian (2020a). Interview I1. Available online at
https://doi.org/10.7910/DVN/FP5RC

W.

- Meißner, Maximilian (2020b). Interview I2. Available online at https://doi.org/10.7910/DVN/FP5RC W.

- Meißner, Maximilian (2020c). Offshore Wind Turbine Cost Scaling. A critical Assesment and theoretical Investigation. In: EAB - Publishing (Ed.). Essays der Wissenschaft. Akademische Essays aus dem Bereich der interdisziplinären Wissenschaften zur Anwendung in Theorie und Praxis (Teil 19 / XIX). 19th ed. Readbox Unipress, 161-183.

- Meißner, Maximilian (2020d). Offshore wind turbine cost structrue analysis. High Technology Letters (Volume 26, Issue 10), 24-38. https://doi.org/10.37896/HTL26.10/1 903.

- Mikkola, Juliana Hsuan (2001). Portfolio management of R\&D projects: implications for innovation management. Technovation (Volume 21, Issue 7), 423-435. https://doi.org/10.1016/S01664972(00)00062-6.

- Olson, Eric M./Walker, Orville C./Ruekerf, Robert W./Bonnerd, Joseph M. (2001). Patterns of cooperation during new product development among marketing, operations and R\&D: Implications for project performance. Journal of Product Innovation Management 18 (4), 258-271. https://doi.org/10.1111/15405885.1840258.

- Ove Arup \& Partners Ltd. Review of Renewable Electricity Generation Cost and Technical Assumptions. Available online at https://assets.publishing.service.gov.u $\mathrm{k} /$ government/uploads/system/uploa ds/attachment_data/file/566718/Aru p_Renewable_Generation_Cost_Report. pdf.

- Siemens Gamesa Renewable Energy (2020). Powered by change: Siemens Gamesa launches 14 MW offshore 
Direct Drive turbine with 222-meter rotor. Press release. Available online at https://www.siemensgamesa.com/enint/-

/media/siemensgamesa/downloads/e n/newsroom/2020/05/siemens-

gamesa-press-release-turbine-14-222dd-en.pdf (accessed 7/19/2020).

- Tolonen, Arto/Shahmarichatghieh, Marzieh/Harkonen, Janne/Haapasalo, Harri (2015). Product portfolio management - Targets and key performance indicators for product portfolio renewal over life cycle. International Journal of Production Economics 170, 468-477. https://doi.org/10.1016/j.ijpe.2015.05 .034 .

- Vestas Wind Systems A/S (2021). Vestas launches the V236-15.0 MW to set new industry benchmark and take next step towards leadership in offshore wind. Available online at https://mb.cision.com/Public/18886/ 3283489/a42e3f67f111dd1e.pdf. 